\title{
Cauda equina redundant nerve roots are associated to the degree of spinal stenosis and to spondylolisthesis
}

\section{Associação entre a presença de raízes redundantes na cauda equina e a área seccional do saco dural avaliada por meio de ressonância magnética}

Leonor Garbin Savarese, Geraldo Dias Ferreira-Neto², Carlos Fernando Pereira da Silva Herrero ${ }^{3}$, Helton Luiz Aparecido Defino ${ }^{3}$, Marcello H. Nogueira-Barbosa ${ }^{1}$

\begin{abstract}
To evaluate the association of redundant nerve roots of cauda equina (RNRCE) with the degree of lumbar spinal stenosis (LSS) and with spondylolisthesis. Method: After Institutional Board approval, 171 consecutive patients were retrospectively enrolled, 105 LSS patients and 66 patients without stenosis. The dural sac cross-sectional area (CSA) was measured on T2w axial MRI at the level of L2-3, L3-4 and L4-5 intervertebral discs. Two blinded radiologists classified cases as exhibiting or not RNRCE in MRI. Intra- and inter-observer reproducibility was assessed. Results: RNRCE were associated with LSS. RRNCE was more frequent when maximum stenosis $<55 \mathrm{~mm}^{2}$. Substantial intra- observer agreement and moderate inter-observer agreement were obtained in the classification of RNRCE. Spondylolisthesis was identified in 27 patients and represented increased risk for RRNCE. Conclusion: LSS is a risk factor for RNRCE, especially for dural sac CSA $<55 \mathrm{~mm}^{2}$. LSS and spondylolisthesis are independent risk factors for RNRCE.
\end{abstract}

Keywords: magnetic resonance imaging, spinal nerve roots, cauda equina, spinal stenosis, spondylolisthesis.

\section{RESUMO}

Avaliar associação entre raízes nervosas redundantes da cauda eqüina (RNRCE) com grau de estenose do canal lombar (ECL) e espondilolistese. Método: Após aprovação do Comitê de Ética, 171 pacientes foram selecionados retrospectivamente, 105 com ECL e 66 sem estenose. Foram realizadas mensurações da área seccional do saco dural em imagens axiais de RM ponderadas em T2 em L2/L3, L3/L4 e L4/ L5. Presença ou não de RRNCE foi classificada de forma independente por dois radiologistas, às cegas. Concordância intra e inter-observador foi analisada. Resultados: RNRCE foi associada à ECL e foi mais freqüente quando a máxima estenose encontrada foi $<55 \mathrm{~mm}^{2}$. Houve grande concordância intra-observador e moderada inter-observador na classificação das RRNCE. Espondilolistese foi identificada em 27 pacientes e representou maior risco para desenvolvimento de RNRCE. Conclusão: ECL é fator de risco para RNRCE, especialmente com áreas seccionais $<55 \mathrm{~mm}^{2}$. ECL e espondilolistese representam fatores de risco independentes para desenvolvimento de RNRCE.

Palavras-chave: ressonância magnética, raizes nervosas, cauda equina, estenose espinhal, espondilolistese.

Redundant nerve roots of the cauda equina (RNRCE) are characterised in magnetic resonance images (MRIs) of the lumbosacral spinal cord by the presence of elongated and tortuous nerve roots with a serpiginous or coiled appearance and near an area of spinal canal stenosis ${ }^{1,2,3,4,5,6,7,8}$. The literature describes this entity in association with degenerative spinal canal stenosis (Figure 1). It is believed that the acquired elongation of the nerve roots is due to a chronic compression force at the level of the lumbar spinal stenosis
(LSS) ${ }^{9}$. This condition is not a new or separate disease but may be part of the natural evolution of lumbar canal stenosis.

The recognition of RNRCE in diagnostic imaging is especially important for avoiding the misdiagnosis of other diseases, such as arteriovenous malformations ${ }^{9}$. The reported prevalence of RNRCE varies, with some researchers determining prevalence values of $33.8 \%$ to $42 \%$ in patients with spinal canal stenosis ${ }^{9,10}$.

\footnotetext{
${ }^{1}$ Departamento de Radiologia, Faculdade de Medicina de Ribeirão Preto, Universidade de São Paulo, Ribeirao Preto SP, Brazil; ${ }^{2}$ Centro de Recursos Diagnósticos, Goiânia GO, Brazil;

${ }^{3}$ Departamento de Biomecânica, Faculdade de Medicina de Ribeirão Preto, Universidade de São Paulo, Ribeirao Preto SP, Brazil.

Correspondence: Leonor Garbin Savarese, Faculdade de Medicina de Ribeirão Preto, Universidade de São Paulo; Av. Bandeirantes $3900 ; 14049-090$ Ribeirao Preto SP, Brasil; E-mail: leonorgs@usp.br

Conflict of interest: There is no conflict of interest to declare.

Received 16 April 2014; Received in final form 03 July 2014; Accepted 23 July 2014.
} 


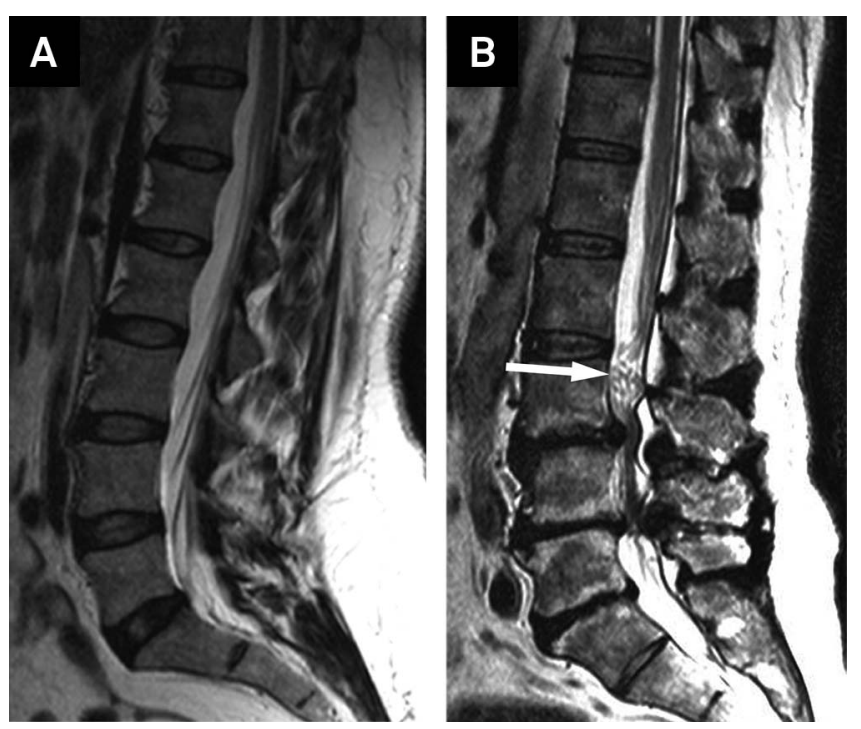

Figure 1. (A) 51-year-old female. Saggital T-weighted MR image shows a normal distribution of the nerve roots of the cauda equine without serpiginous roots. (B) 62-year-old male. Saggital T2-weighted MR image shos lumbar spine degenerative changes, spinal canal stenosis at L3-L4 and L4-L5, and spondylolisthesis at L3-L4. Redundant nerve roots in the cauda equine are illustrated (arrow).

Two recent studies have revealed that patients with a diagnosis of RNRCE by MRI exhibit more severe clinical symptoms in terms of leg pain, paresthesia, and the ability to walk, and show little improvement in their walking ability following decompression surgery compared with patients who do not have $\mathrm{RNRCE}^{10,11}$. Although the results of these studies suggest that RNRCE has clinical significance, this condition has been relatively under-recognised in radiological practice.

The purpose of this study was to evaluate the association of RNRCE with the degree of spinal stenosis as measured by MRI, as well as the association of RNRCE with spondylolisthesis. We hypothesised that the degree of lumbar spinal stenosis and the presence of spondylolisthesis could represent risk factors for developing RNRCE.

\section{METHOD}

This retrospective study was approved by the Research Ethics Committee in the University Hospital (HCRP 7108/ 2010). Consecutive patients undergoing routine MR scans of the lumbosacral spine between 01/01/2009 and 05/31/2010 was selected for potential inclusion in the study group.

The inclusion criterion for the stenosis group was a dural sac $\mathrm{CSA}<100 \mathrm{~mm}^{2}$ in at least one measured level. Patients undergoing MRI for other diseases without a diagnosis of spinal canal stenosis and with CSA measurement $\geq 100 \mathrm{~mm}^{2}$ at all levels were included in the control group. The exclusion criteria for both groups were the following:
1) prior spine surgery, 2) congenital spinal canal stenosis, 3) fractures, 4) neoplasms, 5) ankylosis, 6) inflammatory/infectious diseases, 7) myelopathy or 8) patients who have undergone spinal interventions such as epidural injection or myelography.

A total of 184 patients were diagnosed with lumbar canal stenosis; 105 patients met the inclusion criterion, and 79 patients were excluded because they met at least one of the exclusion criteria. One hundred and forthy one consecutive patients did not exhibit any evidence of spinal stenosis in the routine lumbar spine MR scans. Sixty-six of these patients were included in our study control group, and the remaining 75 patients were excluded because they met at least one of the exclusion criteria. Finally, the study group comprised 171 patients (105 with lumbar spine stenosis and 66 patients without stenosis).

The cross-sectional area (CSA) of the dural sac was measured in axial T2-weighted images at the level of the intervertebral disc spaces L2-L3, L3-L4 and L4-L5 in each patient (Figure 2). The quantitative evaluation of the CSA was performed on MINC (Medical Imaging NetCDF) format images at a workstation with the software Display (McConnel Imaging Centre - McGill University, Montreal, Canada).

The presence or absence of RNRCE was classified separately and independently by two blinded observers based on sagittal T2-weighted images. The observers were a senior spine surgeon and a musculoskeletal radiology fellow. The cases of disagreement between these two observers were analysed by a senior musculoskeletal radiologist with more than 15 years in musculoskeletal radiology and 12 years experience reading spine MRIs. These final classification was used for the statistical analysis.

The same senior musculoskeletal radiologist classified the presence or absence of spondylolisthesis blinded to the other results.

Chi-square test was used to determine whether there was an association between two variables. Additionally, the PROC LOGISTIC procedure was used to calculate the raw odds
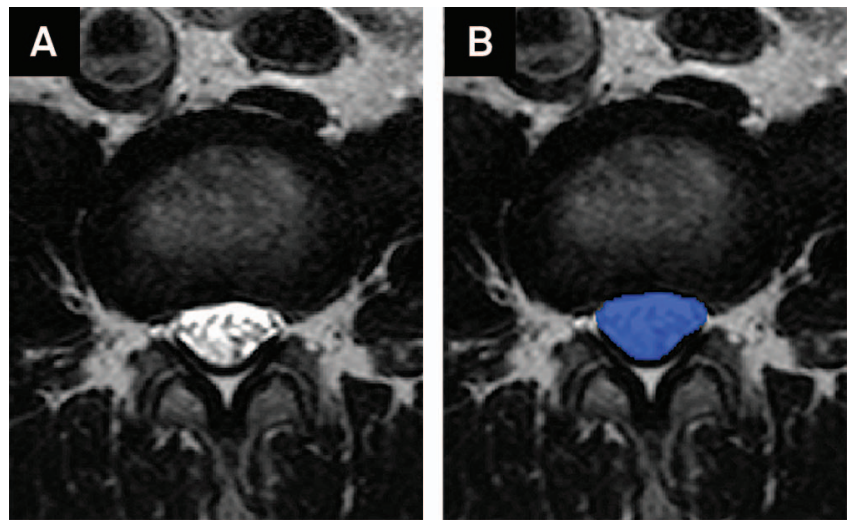

Figure 2. Axial T2-weighted images at the L2-L3 level showing the highlighted segmentation. 
Table 1. Description of the behaviour of the following variables: age; cross-sectional area measured at the level of L2-L3, L3L4, and L4-L5; and maximum stenosis for the groups with and without redundant nerve roots.

\begin{tabular}{|c|c|c|c|c|c|c|c|c|c|c|}
\hline \multirow{2}{*}{ Group } & \multirow{2}{*}{$\begin{array}{l}\text { Presence or absence } \\
\text { of redundancy }\end{array}$} & \multirow{2}{*}{$\mathrm{N}$} & \multirow{2}{*}{ Variable } & \multirow{2}{*}{ Mean } & \multicolumn{2}{|c|}{$95 \% \mathrm{Cl}$} & \multirow{2}{*}{ SD } & \multirow{2}{*}{ Minimum } & \multirow{2}{*}{ Median } & \multirow{2}{*}{ Maximum } \\
\hline & & & & & LL & UP & & & & \\
\hline \multirow[t]{8}{*}{ Control } & No & 60 & Age & 43.83 & 39.83 & 47.84 & 15.5 & 9 & 43.5 & 80 \\
\hline & & & L2/L3 & 197.79 & 188.37 & 207.21 & 36.46 & 118.43 & 196.52 & 319.5 \\
\hline & & & L3/L4 & 172.27 & 163 & 181.54 & 35.88 & 103.71 & 168.91 & 320.13 \\
\hline & & & L4/L5 & 169.9 & 157.41 & 182.38 & 48.34 & 101.01 & 160.13 & 359.65 \\
\hline & Yes & 6 & Age & 58.17 & 50.82 & 65.51 & 7 & 47 & 59 & 67 \\
\hline & & & L2/L3 & 205.64 & 153.08 & 258.19 & 50.08 & 157.98 & 193.25 & 297.73 \\
\hline & & & L3/L4 & 169.95 & 115.9 & 224 & 51.51 & 110.08 & 163.13 & 265.43 \\
\hline & & & L4/L5 & 192.55 & 96.08 & 289.01 & 91.92 & 112.46 & 167.32 & 363.87 \\
\hline \multirow[t]{10}{*}{ Stenosis } & No & 62 & Age & 53.06 & 49.15 & 56.98 & 15.43 & 17 & 54 & 82 \\
\hline & & & L2/L3 & 137.42 & 127.92 & 146.92 & 37.42 & 74.77 & 136.67 & 219.29 \\
\hline & & & $\llcorner 3 /\llcorner 4$ & 111.18 & 102.32 & 120.03 & 34.88 & 34.36 & 110.84 & 192.74 \\
\hline & & & L4/L5 & 73.75 & 66.31 & 81.18 & 29.28 & 21.42 & 71.27 & 178.43 \\
\hline & & & Máx. stenosis & 68.31 & 62.84 & 73.79 & 21.56 & 21.42 & 70.81 & 98.86 \\
\hline & Yes & 43 & Age & 61.67 & 57.77 & 65.58 & 12.68 & 28 & 62 & 89 \\
\hline & & & L2/L3 & 129.62 & 117.11 & 142.13 & 40.66 & 28.45 & 130.93 & 203.25 \\
\hline & & & L3/L4 & 85.23 & 73.44 & 97.02 & 38.3 & 21.34 & 85.47 & 167.87 \\
\hline & & & L4/L5 & 62.37 & 53.38 & 71.35 & 29.19 & 16.7 & 61.56 & 131.55 \\
\hline & & & Máx. stenosis & 51.28 & 44.25 & 58.31 & 22.85 & 16.7 & 50.05 & 99.54 \\
\hline
\end{tabular}

Cl: Confidence interval; SD: Standard deviation; LL: Lower limit; UP: Upper limit.

ratio in each case. Statistical significance was stablished for a p-value less than 0.01 .

To assess intraobserver and interobserver variability in interpreting the images for the RNRCE, kappa coefficient were used to measure the degree of agreement between the readers. A kappa value of 0.41-0.60 indicated moderate agreement, a value of 0.61-0.80 indicated high agreement, and a value of 0.81-1,00 indicated almost perfect agreement ${ }^{13,14,15}$. Simple and multiple logistic regression models were used to control for or to consider the existence of confounding factors ${ }^{16}$ because the response was binary. SAS software (Cary, NC, USA) was used for these analyses.

\section{RESULTS}

Forthy three of the 105 patients included in the spinal canal stenosis group were classified as having RNRCE, whereas 62 patients were classified as not having RNRCE, based on the independent assessment of the senior radiologist. Sixty of the 66 patients included in the control group did not have RNRCE, whereas 6 patients were classified as having this abnormality (Table 1).
The frequency of redundant nerve roots in the sample of individuals with lumbar stenosis was $41 \%$ and in the control group was $9 \%$ (Table 2).

Using the chi-square test, our study confirmed the association between the presence of stenosis and the presence or absence of redundancy $(\mathrm{p}<0.01)$. The calculated odds ratio revealed that the group of patients with spinal canal stenosis were 6.94 times more likely to have RNRCE than were the subjects in the control group (95\%CI 2.75-17.49).

The chi-square test revealed an association between the maximum level of stenosis and the presence or absence of redundancy $(\mathrm{p}<0.01)$ (Table 3$)$. The threshold of $55 \mathrm{~mm}^{2}$ for the CSA of the dural sac was the one most associated with risk of RNRCE.

The calculated odds ratio showed that the group of patients that the dural sac CSA at the point of maximum stenosis measured $<55 \mathrm{~mm}^{2}$ were 4,40 times more likely to have RNRCE than were the group of subjects with a maximum stenosis $>55 \mathrm{~mm}^{2}$ (95\%CI 1,91;10,14). There was a higher frequency of redundancy in the sample of individuals with severe stenosis according to dural sac CSA measurements.

There was a moderate interobserver agreement in the analysis for the presence or absence of redundancy, with a

Table 2. Association between the presence of stenosis and the presence of redundancy (significance level, $p<0.01$ ).

\begin{tabular}{lccccc}
\multirow{2}{*}{ Group } & \multicolumn{2}{c}{ Presence or absence of redundancy $($ Ref $=$ yes $)$} & Total & p-value* & Odds Ratio (95\%Cl) \\
\cline { 2 - 4 } & No & Yes & 6 & 66 & $<0.01$ \\
Control & 60 & $9 \%$ & $100 \%$ & ref \\
Stenosis & $91 \%$ & 43 & 105 & $6.94(2.75 ; 17.49)$ \\
& 62 & $41 \%$ & $100 \%$ & 171 & \\
Total & $59 \%$ & 49 & & \\
\hline
\end{tabular}


Table 3. Association between maximum stenosis and the presence of redundancy (significance level, $p<0.01$ ).

\begin{tabular}{|c|c|c|c|c|c|}
\hline \multirow{2}{*}{ Máx. stenosis (in $\mathrm{mm}^{2}$ ) } & \multicolumn{2}{|c|}{ Presence or absence of redundancy (Ref $=$ yes) } & \multirow{2}{*}{ Total } & \multirow{2}{*}{ p-value* } & \multirow{2}{*}{ Odds Ratio $(95 \% \mathrm{Cl})$} \\
\hline & No & Yes & & & \\
\hline$<55$ & $\begin{array}{c}16 \\
38.1 \%\end{array}$ & $\begin{array}{c}26 \\
61.9 \%\end{array}$ & $\begin{array}{c}42 \\
100 \%\end{array}$ & $<0.01$ & 4,40 (1.91;10.14) \\
\hline$>55$ & $\begin{array}{c}46 \\
73.02 \%\end{array}$ & $\begin{array}{c}17 \\
26.98 \%\end{array}$ & $\begin{array}{c}63 \\
100 \%\end{array}$ & & Ref \\
\hline Total & 62 & 43 & 105 & & \\
\hline
\end{tabular}

Table 4. Association between the presence of spondylolisthesis and the presence of redundancy (significance level, $p<0.01$ ).

\begin{tabular}{|c|c|c|c|c|c|c|c|c|}
\hline \multirow{2}{*}{ Spondylolisthesis } & \multicolumn{2}{|c|}{ Redundancy } & \multirow{2}{*}{ Total } & \multirow{2}{*}{$p$-value } & \multirow{2}{*}{ Raw Odds Ratio (yes X no) } & \multicolumn{2}{|c|}{$95 \% \mathrm{Cl}$} & \multirow{2}{*}{ Raw $p$-value } \\
\hline & No & Yes & & & & LL & UP & \\
\hline No & $\begin{array}{c}110 \\
76.39 \%\end{array}$ & $\begin{array}{c}34 \\
23.61 \%\end{array}$ & $\begin{array}{r}144 \\
100 \%\end{array}$ & $<0.01$ & 4.04 & 1.73 & 9.47 & $<0.01$ \\
\hline \multirow[t]{2}{*}{ Yes } & 12 & 15 & 27 & & & & & \\
\hline & $44.44 \%$ & $55.56 \%$ & $100 \%$ & & & & & \\
\hline Total & 122 & 49 & 171 & & & & & \\
\hline
\end{tabular}

LL: Lower limit; UP: Upper limit.

kappa value of 0.58 (95\%CI 0.46-0.69). The observers agreed on $136(79 \%)$ of the 171 cases.

There was a high intraobserver agreement, with a kappa value of 0.77 (95\%CI 0.66-0.88). The observers were consistent in 155 (90\%) of the 171 cases.

The evaluation using the chi-square test indicated an association between the presence or absence of spondylolisthesis and the presence or absence of redundancy $(\mathrm{p}<0.01)$ (Table 4).

The calculated odds ratio indicated that the group of patients who had spondylolisthesis were four times more likely to exhibit redundancy compared with the group of patients without spondylolisthesis (95\%CI 1.73-9.47).

Simple logistic regression model was used to calculate the raw odds ratio, which confirmed that the stenosis group was seven times more likely to exhibit redundancy compared with the control group. In addition, the spondylolisthesis group was four times more likely to exhibit redundancy than the group without spondylolisthesis.

Using a multiple logistic regression model, the adjusted odds ratio was calculated, indicating that the stenosis group was 6.4 times more likely to exhibit redundancy compared with the control group, and the spondylolisthesis group was 3.5 times more likely to exhibit redundancy than the group without spondylolisthesis.

Because the interpretations of the odds ratio did not change for the other variables, we can state that spondylolisthesis does not affect the relationship between the group "presence or absence of stenosis" and redundancy, and that the group "presence or absence of stenosis" does not affect the relationship between spondylolisthesis and redundancy (Table 5).

\section{DISCUSSION}

RNRCE is a relatively common finding on MRI of the lumbar spine in patients with spinal canal stenosis (Figure 3). Our study statistically confirmed the association between the presence of spinal canal stenosis and redundant nerve roots. Although this association is not new in the literature, previously published studies were either based on case series

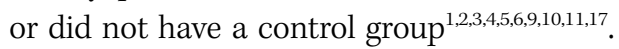

In our study, patients with spinal canal stenosis had a higher likelihood of exhibiting RNRCE compared with the group of patients without stenosis. According to

Table 5. Adjusted logistic regression for the variables stenosis and spondylolisthesis. The effect that the variable presence of stenosis exerts on the variable presence of spondylolisthesis was controlled (significance level, p<0.01).

\begin{tabular}{|c|c|c|c|c|c|c|c|c|}
\hline \multirow{3}{*}{ Variables } & \multicolumn{4}{|c|}{ Crude Regression } & \multicolumn{4}{|c|}{ Adjusted Regression * } \\
\hline & \multirow{2}{*}{$\begin{array}{l}\text { Raw Odds } \\
\text { Ratio }\end{array}$} & \multicolumn{2}{|c|}{$95 \% \mathrm{Cl}$} & \multirow{2}{*}{$\begin{array}{l}\text { Crude } \\
\text { p-value }\end{array}$} & \multirow{2}{*}{$\begin{array}{l}\text { Adjusted Odds } \\
\text { Ratio* }\end{array}$} & \multicolumn{2}{|c|}{$95 \% \mathrm{Cl}$} & \multirow{2}{*}{$\begin{array}{l}\text { Adjusted } \\
\mathrm{p} \text {-value * }\end{array}$} \\
\hline & & LL & UP & & & $\mathrm{LI}$ & LS & \\
\hline Group (stenosis $\times$ control) & 6.94 & 2.75 & 17.49 & $<0.01$ & 6.39 & 2.50 & 16.34 & $<0.01$ \\
\hline Spondylolisthesis (yes x no) & 4.04 & 1.73 & 9.47 & $<0.01$ & 3.46 & 1.40 & 8.57 & $<0.01$ \\
\hline
\end{tabular}

* Adjusted for the variables group and spondylolisthesis. LL: Lower limit; UP: Upper limit. 

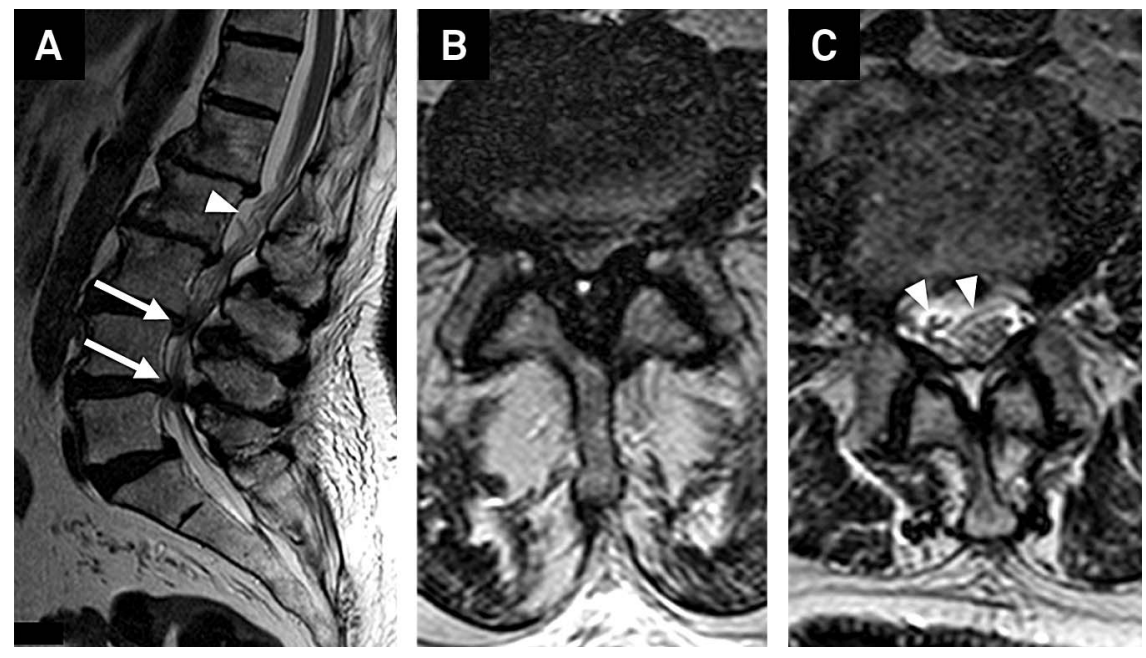

Figure 3. 64-year-old female, with neurogenic claudication. (A) Saggital T2-weighted MR image shows the degenerative changes and disc herniations with special canal stenosis at L3-L4 and L4-L5 (arrows). The cauda equine nerve roots exhibit a wavy orientation (arrow heads). Spondylolisthesis is also present at L5-51. (B) Axial T2-weighted MR images at the height of L4-45 shows the degenerative changes, especially the thickening of the yellow ligaments. (C) Axial T2-weighted MR images in the abovedescribed stenoids provides evidence for serpiginous and slightly thickened nerve roots (arrow heads).

Suzuki et al., RNRCE is most likely the pathological result of a chronic compression force at the level of spinal canal stenosis ${ }^{9}$. This study with histopathologic evaluation identified nerve fibers degeneration and neuronal loss due to continuous mechanical compression of the nerve roots, which were confined in the narrowed spinal canal ${ }^{17}$.

Furthermore, patients with the smaller dural sac CSAs at the point of maximum stenosis had an increased risk of developing RNRCE. A higher percentage of redundancy was encountered in the group of patients who had greater spinal canal stenosis. A possible explanation for this finding would be that the more constricted the spinal canal, the more the nerve roots will suffer and thicken, acquiring a redundant aspect on MRI.

Suzuki et al. examined a group of 130 patients with severe canal stenosis (with complete or incomplete blocking of contrast on myelogram) divided into two groups based on the presence or absence of redundancy ${ }^{17}$. The degree of stenosis was divided into complete or incomplete blockage, and the degree of the constriction was significantly correlated with the presence of RNRCE. However, the study design yielded a naturally biased sampling because only patients who had a severely constricted spinal canal were included.

Ono et al. examined 44 cases with stenosis secondary to spondylolisthesis at L4-L5, in which a myelogram revealed complete blockage of the canal ${ }^{10}$. The dural sac CSA at the point of maximum stenosis was measured and no statistically significant difference was found between the groups that were analysed. However, the same study demonstrated selection bias because only patients with severe stenosis and complete blockage of the canal in the myelogram were included.

Min et al. examined 68 patients who underwent decompressive laminectomy and divided them into two groups based on the presence or absence of redundancy. Patients with instability or spinal canal stenosis at multiple levels were excluded $^{11}$. This study did not report a significant correlation between the degree of stenosis and the prevalence of RNRCE, but there were two important limiting factors. First, related to the methodology, since the researchers measured stenosis via the anteroposterior diameter in the MRI and not via the dural sac CSA. The CSA measurements of the dural sac have previously been emphasised as the best option for studying spinal canal stenosis ${ }^{18,19,20}$. CSA measurements via MRI yield a high interobserver reproducibility ${ }^{21}$. The second limitation is related to patient selection bias, since in that study only patients who were undergoing surgery for spinal canal decompression were evaluated.

Our study has some limitations. It was a retrospective study and the clinical correlation was not available. This prevents us from making conclusions about the clinical management of patients with RNRCE. Also, the assessment of the stenosis degree was determined from static MR scans obtained from patients in a supine position rather than in a standing position. This is not expected to be a great problem since most often MRI in the supine position is able to identify lumbar stenosis.

We objectively assessed the full lumbar spinal canal stenosis by measuring the CSA of the dural sac. Furthermore, our sample consisted of patients with at least one measurement less than $100 \mathrm{~mm}^{2}$, which is in contrast with the sampling of previous studies that consisted of patients who always exhibited severe stenosis, underwent decompression surgery, or had a complete contrast blockage that was visible on myelogram. To our knowledge, this study is the first to demonstrate a statistically significant association between the presence of redundant nerve roots and the degree of spinal canal stenosis. 
Our results demonstrated the association between spondylolisthesis and the presence of redundancy; patients with spondylolisthesis had a higher risk of RNRCE compared with patients without spondylolisthesis. Spinal canal stenosis and spondylolisthesis were shown to be independent risk factors for the presence of RNRCE.
In conclusion the results of this study indicate that lumbar stenosis identified using dural sac CSA measurements by MRI is a risk factor for RNRCE, especially for a lumbar dural sac CSA $<50 \mathrm{~mm}^{2}$. Based on our results, lumbar stenosis and spondylolisthesis represent independent risk factors for the development of RNRCE.

\section{REFERENCES}

1. Cressman MR, Pawl RP. Serpentine myelogramic defect caused by a redundant nerve root: case report. J Neurosurg. 1968;28(4):391-3. http://dx.doi.org/10.3171/jns.1968.28.4.0391

2. Tribolet N, Campiche R. Redundant nerve roots of the cauda equina. A rare disease? Eur Neurol. 1982;21(3):169-74. http://dx.doi.org/ 10.1159/000115476

3. Duncan AW, Kido DK. Serpentine cauda equina nerve roots. Radiology. 1981;139(1):109-11. http://dx.doi.org/10.1148/radiology.139.1.7208911

4. Ehni G, Moiel RH, Bragg TG. The "redundant" or "knotted" nerve root: a clue to spondylotic cauda equina radiculopathy: case report. J Neurosurg. 1970;32(2):252-4. http://dx.doi.org/10.3171/ jns.1970.32.2.0252

5. Fox JL. Redundant nerve roots in the cauda equina: case report. J Neurosurg. 1969;30(1):74-5. http://dx.doi.org/10.3171/jns.1969.30.1.0074

6. Gulati DR, Rout D. Myelogramic block caused by redundant lumbar nerve root. Case report. J Neurosurg. 1973;38(4):504-5. http://dx.doi. org/10.3171/jns.1973.38.4.0504

7. Nogueira-Barbosa MH, Savarese LG, Herrero CFPS, Defino HLA. Redundant nerve roots of the cauda equina: review of the literature. Radiol Bras. 2012;45(3):155-9. 10.1590/s0100-39842012000300007

8. Hacker DA, Latchaw RE, Yock DH Jr, Ghosharjura K, Gold LH. Redundant lumbar nerve root syndrome: myelogramic features. Radiology. 1982;143(2):457-61. http://dx.doi.org/10.1148/radiology.143. 2.6280235

9. Suzuki K, Ishida Y, Ohmori K, Sakai H, Hashizume Y. Redundant nerve roots of the cauda equina: clinical aspects and consideration of pathogenesis. Neurosurgery. 1989;24(4):521-8. http://dx.doi.org/ 10.1097/00006123-198904000-00006

10. Ono A, Suetsuna F, Irie T, Yokoyama T, Numasawa T, Wada K et al. Clinical significance of the redundant nerve roots of the cauda equina documented on magnetic resonance imaging. J Neurosurg Spine. 2007;7(1):27-32. http://dx.doi.org/10.3171/SPI-07/07/027

11. Min J-H, Jang J-S, Lee S-H. Clinical significance of redundant nerve roots of the cauda equina in lumbar spinal stenosis. Clin Neurol
Neurosurg. 2008;110(1):14-8. http://dx.doi.org/10.1016/j.clineuro. 2007.08.005

12. Bolender NF, Schönström NS, Spengler DM. Role of computed tomography and myelography in the diagnosis of central spinal stenosis. J Bone Joint Surg Am. 1985;67(2):240-6. http://dx.doi.org/ 10.1097/00007632-198511000-00005

13. Cohen, J. A coefficient of agreement for nominal scales. Edu Psychol Measur. 1960;20(1):37-46. http://dx.doi.org/10.1177/ 001316446002000104

14. Landis JR, Koch GG. The measurement of observer agreement for categorical data. Biometrics. 1977;33(1):159-74. http://dx.doi.org/ $10.2307 / 2529310$

15. Agresti A. Categorical data analysis. New York: John Wiley; 2000.

16. Hosmer DW, Lemeshow S. Applied logistic regression. 2nd ed. New York: John Willey \& Sons; 2000.

17. Suzuki K, Takatsu $T$, Inoue $H$, Teramoto $T$, Ishida $Y$, Ohmori $K$. Redundant nerve roots of the cauda equina caused by lumbar spinal canal stenosis. Spine. 1982;17(11):1337-42. http://dx.doi.org/ 10.1097/00007632-199211000-00013

18. Scönström NSR, Bolender NF, Spengler DM, Hansson T. Pressure changes within the cauda equina following constriction of the dural sac: an in vitro experimental study. Spine. 1984;9(6):604-7. http://dx.doi.org/10.1097/00007632-198409000-00011

19. Schönström NSR, Bolender NF, Spengler DM. The pathomorphology of spinal stenosis as observed on CT scans of the lumbar spine. Spine. 1985;10(9):806-11. http://dx.doi.org/10.1097/00007632-19851100000005

20. Zheng F, Farmer JC, Sandhu HS, O'Leary PF. A novel method for the quantitative evaluation of lumbar spinal stenosis. HSSJ. 2006;2(2):136-40. http://dx.doi.org/10.1007/s11420-006-9006-3

21. Lurie JD, Tosteson AN, Tosteson TD, Carragee E, Carrino JA, Carrino J et al. Reliability of readings of magnetic resonance imaging features of lumbar spinal stenosis. Spine. 2008;33(14):1605-10. http://dx.doi. org/10.1097/brs.0b013e3181791af3 